ORIGINAL ARTICLE

\title{
Prevalence of Staphylococcus aureus carriage by young Malaysian footballers during indoor training
}

\author{
J L William, S Radu, S A Aziz, R A Rahim, Y K Cheah, A Liwan, S Lihan
}

Br J Sports Med 2004;38:12-14. doi: 10.1136/bjsm.2002.000653

See end of article for authors' affiliations

......................

Correspondence to: J L William, University Putra, Malaysia;

laurence_john@

hotmail.com

Accepted 14 January 2003

\begin{abstract}
Background: Research has shown that athletes are carrriers of Staphylococcus aureus during physical activity.

Objective: To estimate the mean total plate count of $S$ aureus carrried by footballers before and after training at an indoor venue.

Methods: Forty Malay and 20 Indian students volunteered to participate. There was also a control group consisting of 40 Malay and 20 Indian students who were not active. The experimental group were active footballers who had played at school or club level. The subjects were healthy and free of skin infection. The experiment was divided into three sessions, with 20 subjects present at each. At each session, the subjects trained for one hour. Swabs were taken from the skin, nose, and ear before and after training. For the control group, swabs were taken only once from the skin, nose, and ear. The swabs were subjected to biochemical tests and then streaked and cultured aerobically in Baird Parker agar plates for 24 hours at $37^{\circ} \mathrm{C}$. Black colonies with a clear zone were presumed to be $S$ aureus, and the mean total plate count of the colonies was estimated. Gram staining, catalase, coagulase slide, coagulase tube, acetoin production, o-nitrophenyl $\beta$-D-galactopyranoside (ONPG), and mannitol fermentation tests were used to confirm the colonies as $S$ aureus. A haemolysin test was conducted with human blood to confirm haemolytic activity. Results: All subjects in the experimental group were carrying $S$ aureus both before and after training. The estimated mean total counts of colonies from the skin, ear, and nose for the Malays before training were 33,71 , and 312 respectively. Counts after training were 21,44 , and 452 respectively. The results for the Indians were 72, 80, and 309 respectively before training and 55, 200, and 466 respectively after training. The positive results for Gram staining, catalase, coagulase slide, coagulase tube, acetoin production, ONPG, and mannitol fermentation tests were 100\%, 96\%, 95\%, 95\%, 93\%, 93\%, and 90\% respectively. All subjects in the control group were also carrying $S$ aureus.

Conclusions: All of the players were carriers of $S$ aureus during training. The decrease in total count from the skin for both races may be due to lysozyme activity lysing the bacterial cells. Contamination of the environment with these bacteria may have increased the estimated total plate count in the nose. The experimental group face a higher risk of infection because of lower immunity during training and higher rate of injuries compared with the control group.
\end{abstract}

$\mathrm{O}$ ver the past decade physical activity has become important in our daily lives, and the number of participants in various forms has increased considerably in recent years. ${ }^{12}$ This increase in physical activity participation is not surprising because of the potential benefits. ${ }^{3-5}$ However, a major problem is the high incidence of injury. ${ }^{3}$ Most injuries occur in physical contact sports. Participants in such sports need to be optimally fit to withstand the constant physical contact that may cause injury. ${ }^{6}$

The athlete may also be exposed to bacterial infection. A common bacterium that may cause harm to an injured athlete is Staphylococcus aureus, which is found in moist warm places such as the skin and mucous membranous area of the nose, mouth, and throat. ${ }^{78}$ The name comes from "staphyle" meaning a bunch of grapes and "coccus" meaning round or spherical. ${ }^{9}$ This bacterium can be grouped with the opportunistic pathogens and can produce serious infection. ${ }^{90} S$ aureus is an important cause of soft tissue infection. ${ }^{112}$ The pathogen usually colonises host tissues that are in contact with the external environment, and therefore open wound injuries are at risk. In later stages, it is able to invade the bloodstream. ${ }^{13}$ Invasion of host defence mechanisms can be life threatening in an injured athlete. In general, once the bacterium has colonised the host's defences, it releases toxins into the bloodstream. This may cause diseases such as sepsis, endocarditis, pneumonia, enteritis, osteomyelitis, hepatic, abscess, impetigo, and cellulitis. ${ }^{13}{ }^{14}$ A number of studies have been carried out on $S$ aureus infection in athletes. Stacey $e t \mathrm{al}^{15}$ found that five rugby players were infected with $S$ aureus. One was found to be carrying the bacterium in his nose. He was treated with either erythromycin or clarithromycin and recovered well. A similar study was carried out by Hodde et $a l^{16}$ on a 21 year old collegiate wrestler with acute pain at the left lower quadrant abdominal. A blood sample showed $S$ aureus infection.

The objective of our research was to determine the number of athletes carrying $S$ aureus before and after a session of indoor training.

\section{MATERIALS AND METHODS \\ Subjects}

An experimental group comprised 60 male students, 40 Malays and 20 Indians. A control group also comprised 60 male students with the same ratio of Malays and Indians. The students were all medically fit, free from injuries and skin infection. All were from a secondary school in Malaysia and ranged in age from 13 to 15 years. They were active footballers and had played for either the school or clubs. Before the study, the students provided written informed 
consent. Individual biodata, name, date of birth, race, and health status were obtained before the study. During the period of the study, none of the subjects were taking any prescribed drugs.

\section{Orientation test}

All subjects in the experimental group had two orientation sessions before the experiment to familiarise themselves with the test procedures and techniques. They were not allowed to consume alcohol and drinks with caffeine during the experiments. Both the orientation tests were held in the morning at an indoor venue. All the subjects followed the rules and conditions of the test during the orientation sessions.

\section{Test protocol}

The experiment was divided into three training sessions, with 20 subjects at each. Subjects in the control group rested in a room during the period of the experiment. Each training session was conducted for an hour during the morning. The subjects wore their own sports attire during training sessions and used their own towels but soap was provided. They reported to the training venue an hour before the experiment. They were then instructed to bathe with the soap provided. Sterile cotton buds were used to take swabs from the skin (thigh), nose, and ear of each subject after they had bathed. The swabs were stored in individual sterile universal bottles at $0^{\circ} \mathrm{C}$ for 45 minutes and taken immediately to the laboratory for isolation and further biochemical tests. Three colonies were isolated from each plate and stored for further biochemical tests to identify $S$ aureus species.

\section{Biochemical tests}

All cotton swabs were streaked on to specific prepared Baird Parker agar plates which were incubated under aerobic condition for 24 hours at $37^{\circ} \mathrm{C}$. Colonies with black and clear zones were presumed to be $S$ aureus species, and the mean total count of colonies was estimated from each plate. Three colonies from each plate were selected and stored in glycerol at $-20^{\circ} \mathrm{C}$. Twenty colonies from Malays and 10 from Indians were selected randomly for further biochemical tests to confirm the strain of $S$ aureus. The biochemical tests were conducted at the Microbiology Laboratory, University Putra, Malaysia. The colonies were selected for identification on the basis of morphological characteristics. The standard identification tests were Gram staining and catalase and coagulase production by the slide agglutination test and confirmed by the tube coagulase test, acetoin production, $o$-nitrophenyl $\beta$ D-galactopyranoside test (ONPG) and mannitol fermentation. We also carried out the haemolysin test with human blood to confirm the haemolytic activity of the bacteria.

\section{RESULTS}

\section{Basic data on the subjects}

The mean (SD) age of the subjects was 14.5 (0.5) years (range 13-15). The age gap between the subjects was small. In contrast, there was a large difference in weight between the subjects: minimum $35 \mathrm{~kg}$ and maximum $58 \mathrm{~kg}$. Both the Malays and Indians had a mean (SD) weight of 49.3 (5.5) kg. Mean (SD) height was 155.7 (3.5) cm (range 152.5-175.2).

\section{$S$ aureus carriers}

Table 1 shows the number of subjects carrying $S$ aureus before and after training. Before training, all of the Malays and Indians were carrying the organism on their skin, $90 \%$ of the Malays and $100 \%$ of the Indians were carrying it in their nose, and $80 \%$ of the Indians and $100 \%$ of the Malays carried it in their ear. After training, the numbers of carriers in the nose for both the Malays and Indians was the same as before
Table 1 Number of Staphylococcus aureus carriers during indoor training $(n=60)$

\begin{tabular}{|c|c|c|c|c|}
\hline \multirow[b]{2}{*}{ Site } & \multicolumn{2}{|c|}{ Before training } & \multicolumn{2}{|c|}{ After training } \\
\hline & Malay & Indian & Malay & Indian \\
\hline Skin & $40(40)$ & $20(20)$ & 24 & 20 \\
\hline Nose & 36 (38) & 20 (19) & 36 & 20 \\
\hline Ear & $40(40)$ & 16 (19) & 40 & 20 \\
\hline
\end{tabular}

training. However, only $60 \%$ of the Malays carried the organism on their skin after training compared with 100\% before training, whereas for the Indians the numbers remained the same after training. However, more Indians carried it in the ear after training; the number had increased to $100 \%$, whereas for the Malays the number remained at $100 \%$. Table 1 also gives the results for the control group.

\section{Total plate count of $S$ aureus}

Table 2 shows the estimated total count of $S$ aureus colonies from the three sites. The estimated mean total count from the Malays was reduced, after training, at the skin and ear (from 33 to 21 and from 71 to 44 , respectively) but had increased in the nose (from 312 to 452). The results for the Indians differed. The count for the skin was 72 before training and 55 after training. At the other two sites, the count was increased after training, from 80 to 200 for the ear and from 309 to 466 for the nose.

\section{Biochemical and haemolysis tests}

In the biochemical tests, we found that $96 \%$ were positive for catalase, whereas for the coagulase slide, coagulase tube, acetoin production, o-nitrophenyl $\beta$-D-galactopyranoside (ONPG), and mannitol fermentation tests, the result were $95 \%, 95 \%, 93 \%, 93 \%$, and $90 \%$ respectively. In addition, we found that $100 \%$ of the strains were Gram positive, and $87 \%$ of the strains produced either $\alpha$ or $\beta$ haemolysis.

\section{DISCUSSION}

One interesting finding is that most of the students in both the experimental and control group were carriers of $S$ aureus. However, although subjects in the control group were carriers, the risk of the bacteria causing them harm was lower than for the active students. Athletes carrying out strenuous intense training are at higher risk of infection. Intense training affects certain immune variables that are important to the host in fighting bacterial infection. ${ }^{17} 18$ During intense training, pathogens may invade the bloodstream and cause health problems. Open wound injuries in athletes provide another channel for infection as the tissues are exposed to the environment. $S$ aureus is a normal flora and can be found in many conditions. Furthermore, the species can grow over a wide temperature range $\left(6.5-50^{\circ} \mathrm{C}\right)$, and the mean body temperature during training was $40^{\circ} \mathrm{C}$. This may explain why most of the subjects were carriers of $S$ aureus.

A large number of $S$ aureus strains produce either $\alpha$ or $\beta$ haemolysis, indicating their potential to cause medical problems. Both toxins are able to lyse red blood cells, but the most important is the $\alpha$ toxin, which can cause necrosis

\section{Take home message}

Maintaining good health and hygiene is a key factor in athletic performance. 
Table 2 Staphylococcus aureus plate count before and after training at an indoor venue ( $n=60)$

\begin{tabular}{|c|c|c|c|c|c|c|c|c|}
\hline \multirow[b]{3}{*}{ Site } & \multicolumn{4}{|c|}{ Total count (Malay) } & \multicolumn{4}{|c|}{ Total count (Indian) } \\
\hline & \multicolumn{2}{|l|}{ Before } & \multicolumn{2}{|l|}{ After } & \multicolumn{2}{|l|}{ Before } & \multicolumn{2}{|l|}{ After } \\
\hline & Mean & Range & Mean & Range & Mean & Range & Mean & Range \\
\hline Skin & 33 & $1-95$ & 21 & $0-85$ & 72 & 5-94 & 55 & $15-86$ \\
\hline Ear & 71 & 5-110 & 44 & $0-106$ & 80 & $44-120$ & 200 & $14-294$ \\
\hline Nose & 312 & $0-350$ & 452 & $2-520$ & 309 & $0-410$ & 466 & $3-495$ \\
\hline
\end{tabular}

of the skin. ${ }^{19}$ Hence these toxins could play an important role in affecting performance if infection were present.

From our results, it can be seen that a large proportion of the colonies were positive in the catalase and coagulase slide and tube tests. Nai et $a l^{13}$ obtained a similar result where a large number of the strains were positive for the coagulase test. This also indicates the potential danger from the bacteria if an athlete has an infection.

Our findings also show that the estimated total plate count for both Malays and Indians on the skin had decreased after training. During aerobic training, the core body temperature may increase to above $40^{\circ} \mathrm{C}$. Performance may be impaired when the core temperature is very high. The core temperature is controlled by the hypothalamus. If core temperature is above the set point of the hypothalamus, there is a discharge of efferent impulses from its anterior portion to induce mechanisms for heat removal. ${ }^{20}$ Sweating is usually needed to dissipate the extra heat caused by the increase in metabolic rate. Sweat is produced from the skin and contains lysozyme. Lysozyme is a natural body defence substance which protects the body from infection and has the ability to lyse and inhibit bacteria of many species. ${ }^{21}$ It may be one explanation for the reduced bacteria on the skin of both Malays and Indians after training.

In contrast, our findings show that $S$ aureus had increased in the nose after training in both Malays and Indians. The demand for oxygen is high during aerobic training. Oxygen is the main element used in aerobic glycolysis, where glycogen or glucose is broken down to ATP. ATP is the energy substrate required to perform aerobic activity, and therefore the subjects needed to inhale more oxygen through the nose and mouth during training for energy production. During inhalation, large amounts of bacteria from the air probably enter the nose and are trapped in the nasal passages. Our findings show that the estimated total plate count for swabs from the nose increased for both the Malays and Indians. This may be the main point of entry for bacteria into the body of the host causing higher risk of infection.

The information from this study should help athletes to avoid health problems. Meanwhile other than training, it is important for athletes to pay attention to daily hygiene to avoid health problems and bacterial infection. Wearing clean kit, having a good shower, and proper treatment of wounds are some additional suggestions for reducing bacterial infection in athletes.

\section{Authors' affiliations}

J L William, S Radu, S A Aziz, R A Rahim, Y K Cheah, A Liwan, S Lihan, University Putra, Malaysia

\section{REFERENCES}

1 Nichols JF, Robinson D, Douglass D, et al. Retraining of competitive master athlete following traumatic injury: a case study. Med Sci Sports Exerc 2000;32:1037-42.

2 Kolt GS, Kirkby RJ. Epidemiology of injury in elite and subelite female gymnasts: a comparison of retrospective and prospective findings. $\mathrm{Br} J$ Sports Med 1999;33:312-18.

3 Finch C, Owen N, Price R. Current injury or disability as a barrier to being more physically active. Med Sci Sports Exerc 2001;33:778-82.

4 Howley ET. Type of activity: resistance, aerobic and leisure versus occupational physical activity. Med Sci Sports Exerc 2001;33:S364-9.

5 Drowatzky LK, Brown SA, Kirkner JG, et al. Prevalence of physical activity among South Carolina adults. J S C Med Assoc 2001;97:333-7.

6 Stevenson MR, Hamer P, Finch CF, et al. Sport, age, and sex specific incidence of sport injuries in Western Australia. Br J Sports Med 2000;34: 188-94.

7 Brock TD, Madigan MT. Biology of microorganisms. 5th ed. Englewood Cliffs, NJ: Prentice Hall, 1988.

8 Hu X, Totake K. Molecular typing of Staphylococcus epidermidis and other CNS with repetitive element sequence-based PCR. Microbiol Immunol 1997;41:933-8.

9 Dolbow D, TRK. Methicillin-resistant Staphylococcus aureus. Clinical Kinesiology 1994:61-3.

10 Ramos RLB, Teixeira LA, Ormonde LR, et al. Emergence of mupirocin resistance in multiresistant Staphylococcus aureus clinical isolates belonging to Brazilian epidemic clone III:B:A. J Med Microbiol 1999;48:303-7.

11 Murai M, Seki K, Sakurada J, et al. Subcutaneous growth of Staphylococcus aureus concomitantly inoculated with ehrlich ascites tumor cells. Microbiol Immunol 1995:39:725-8.

12 Marchese A, Schito CG, Debbia AE. Emergence of drug resistant gram positive pathogenic bacteria. J Chemother 2000;12:12-4.

13 Nai AKA, Ogunniyi AD, Lamikanra A, et al. The characterization of clinical isolates of Staphylococcus aureus in lie-Ife, Nigeria. J Med Microbiol 1991;34:109-12

14 Kanclerski K, Soderquist B, Kjellgren M, et al. Serum antibody response to Staphylococcus aureus enterotoxins and TSST- 1 in patients with septicaemia. J Med Microbiol 1996;44:171-7.

15 Stacey AR, Endersby KE, Chan PC, et al. An outbreak of methicillin resistant Staphylococcus aureus infection in a rugby football team. Br J Sports Med 1998;32:153-4.

16 Hodde PJ, Badylak FS, May LC, et al. Infective endocarditis in a collegiate wrestler. Journal of Athletic Training 1995;30:105-7.

17 Mackinnon LT. Immunity in athletes. Int J Sports Med 1997;18:S62-8.

18 Mackinnon LT. Chronic exercise training effects on immune function. Med Sci Sports Exerc 2000;32:S369-76.

19 Levinson W, Jawetza E. Medical microbiology and immunology. London: Appleton and Lange, 1996.

20 Galloway RSD, Shirreffs MS, Maughan JR. Exercise in the heat: factors limiting exercise capacity and methods for improving heat tolerance. Sport and Exercise Injury 1997;3:19-24.

21 Millar M. The susceptibility to lysozyme of $\beta$-lactamase producing and nonproducing derivatives of Staphylococcus aureus strain 1030. J Med Microbiol 1987;23:127-32. 